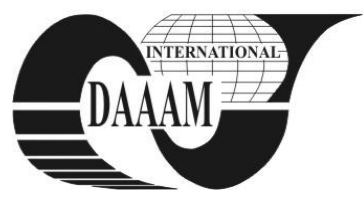

Annals of DAAAM for 2011 \& Proceedings of the 22nd International DAAAM Symposium, Volume 22, No. 1, ISSN 1726-9679 ISBN 978-3-901509-83-4, Editor B. Katalinic, Published by DAAAM International, Vienna, Austria, EU, 2011 Make Harmony between Technology and Nature, and Your Mind will Fly Free as a Bird

Annals \& Proceedings of DAAAM International 2011

\title{
THERMOGRAPHY AND POSSIBILITIES OF ITS APPLICATION IN PRACTICE
}

\author{
FRANKO, S[tefan]; BABUSOVA, E[va] \& BADIDA, M[iroslav]
}

\begin{abstract}
Thermography and thermal imaging are recognized and important part of the techniques and technologies utilized not only in engineering practice, such as are engineering, construction, transport, telecommunications, but also in medicine, special applications and ecology. Aim of this paper is to get more information about thermography and its use in general practice, focusing on its use in the field of mechanical engineering.

Key words: thermography, thermal imaging, thermal imaging system, measurement
\end{abstract}

\section{INTRODUCTION}

Thermal vision, also known as thermography or thermal imaging, is the way the human eye is able to perceive the infrared part of spectrum. Some types of night vision system use thermal vision, and thermography is currently considered the best kind of night vision because they can detect objects in complete darkness. Thermography is widely used in the sphere of security, military, navigation, rescue areas, fire areas, industry, medicine and science.

\section{ELECTROMAGNETIC RADIATION}

Electromagnetic radiation (EM or EMR for short electromagnetic radiation) is a phenomenon that takes the form of self-proliferating waves in a vacuum or in matter. EM consists of electric and magnetic field components. These two components oscillate in phase perpendicular to each other and also perpendicular to the direction of propagation of energy. Electromagnetic radiation is classified by its frequency of waves. With increasing frequency and decreasing wavelength, the waves are distinguished into:

- radio waves,

- microwaves,

- infrared radiation,

- visible light,

- ultraviolet radiation,

- X-ray radiation,

- gama rays.

\section{INFRARED RADIATION}

Infrared means "below red". The name is derived from the Latin infra (meaning "under") and red is the color of the longest wavelength of visible light. Infrared light has a higher wavelength and lower frequency than that which is visible to the human eye. Infrared radiation (IR) is electromagnetic radiation with a wavelength between 0.7 to 300 microns, which is approximately equal to the frequency range between 1 to 430 THz. Infrared wavelengths are longer wavelengths than visible light but shorter than microwave wavelengths of terahertz radiation.

International Commission on Illumination recommends splitting infrared radiation into the following three groups:
- $\quad$ IR-A: $750 \mathrm{~nm}-1400 \mathrm{~nm}(0.75 \mu \mathrm{m}-1.4 \mu \mathrm{m})$

- $\quad$ IR-B: $1400 \mathrm{~nm}-3000 \mathrm{~nm}(1.4 \mu \mathrm{m}-3 \mu \mathrm{m})$

- $\quad$ IR-C: $3000 \mathrm{~nm}-1 \mathrm{~mm}(3 \mu \mathrm{m}-1000 \mu \mathrm{m})$.

Infrared technology can be divided according to infrared spectrum in which it works. Currently they are usually offered by systems that operate in three bands:

- in the near infrared spectrum - NWIR (near infrared wavelength region, where NIR-near infrared region), with wavelengths of $0.75 \mu \mathrm{m}$ to $3 \mathrm{~mm}$, and

- $\quad$ in the central area infrared spectrum - MWIR (middle wavelength infrared region), with wavelengths of $3 \mathrm{~mm}$ to $5 \mathrm{~mm}$,

- in a far area of the infrared spectrum - the LWIR (long wavelength infrared region), with wavelengths of $5 \mathrm{~mm}$ to $15 \mu . \mathrm{m}$.

\section{THERMOGRAPHY IN PRACTICE}

\subsection{Energy}

Predictive maintenance and periodic inspection, diagnosis and monitoring of energy distribution equipment have not only safety significance, but also significant economic effect, because knowledge of the monitoring and evaluation of measured data (bad current joint) can be used to assume outage of high voltage lines up to several hours.

On the basis of the prepared methodology for measuring the external power lines, recommendations are:

- measurements carried out at least $50 \%$ of load,

- terminals or connections, which are fine, should not be hotter than the driver, to which they are attached.
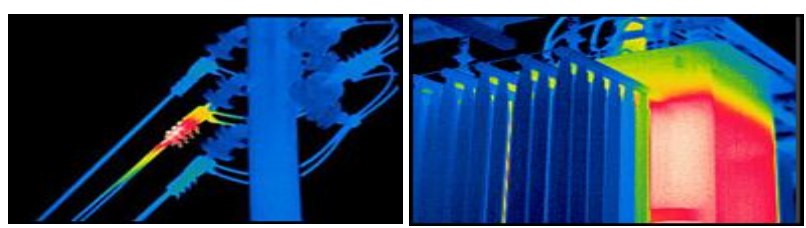

Fig. 1. Infrared pictures of transformator

\subsection{Telecommunications}

This technique has increasingly started to apply even in this sector in recent years. Complex antenna systems are very sensitive to deterioration in transition resistance of antenna nodes. Deterioration of the transition resistance decreases emitted power transmitter and the resulting heat loss transitions.

Control should be focused on the following elements:

- maintenance of antenna's power distribution,

- maintenance of antenna itself,

- maintenance of shifters. 

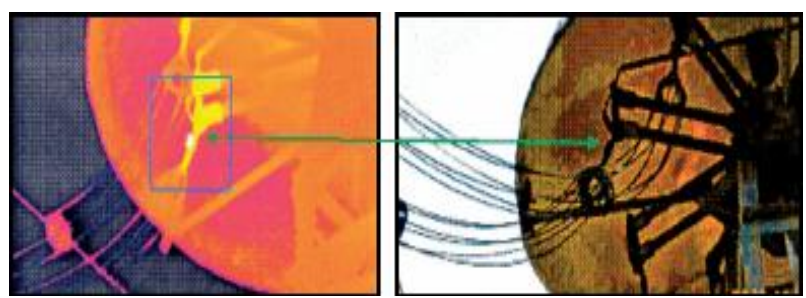

Fig. 2. Infrared pictures of antenna system

\subsection{Contructions}

If we want to prevent undesirable leakage energy, we must first locate the place and cause of loss. One method of dealing with the leakage of heat energy is thermography. The purpose of most infrared measurements in construction is the determination of surface temperatures in the building envelope and determine whether the distribution of surface temperature is "atypical", ie whether it is caused, for example by incorrect construction works, problems with insulation, windows and door leaks, condensation of moisture.

- survey of heat loss in buildings,

- troubleshooting for floor heating,

- check technological equipment of buildings,

- search cracks in the building walls.
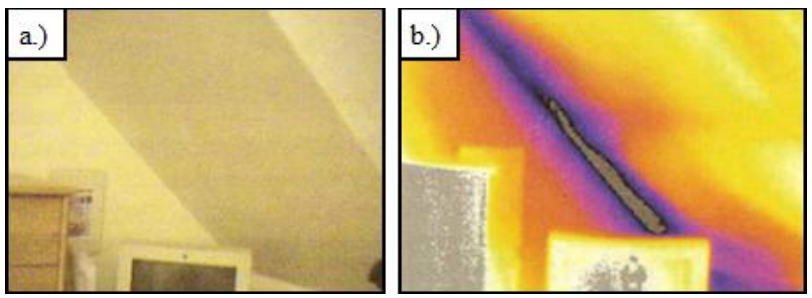

Fig. 3. Infrared pictures of roof - inside; a) normal view,b) infrared view

\subsection{Medicine}

By using thermal vision focal disease processes can be detected, which depend on the temperature difference of focus and surrounding healthy tissue, depth of deposit of focus stage of the disease process, sensitivity and geometric resolution of the thermographic equipment etc. It is a method with low specificity, but it provides important information on the extent and dynamics of the disease process and in conjunction with other methods can help to determine the nature of the disease. Thermographic examinations can be done in a room with constant temperature in the range of 19 to $21^{\circ} \mathrm{C}$. Investigated part of the body should be bare for at least 15 to 20 minutes before testing.
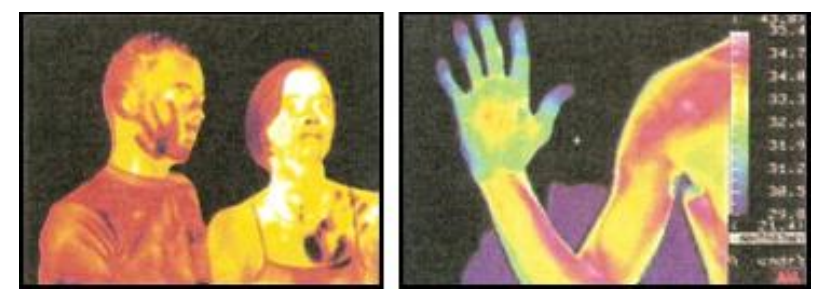

Fig. 4. Infrared pictures of human body's parts

\subsection{Ecology}

This is currently very topical area in which thermal imagin is used to obtain information for improving the environment. It may be used for further diagnosis, i.e. increased temperature in water ponds caused by insufficient water flow, which are a danger to animals, plants, etc. On the basis of thermal imaging and assesing the ground, we can get information about:

- thermal pollution of water,

- monitoring subsurface fires,

- monitoring of landfill gas,

- composting,
- monitoring of microclimate

- exhaust monitoring,

- forest fires,

- gas leaks.

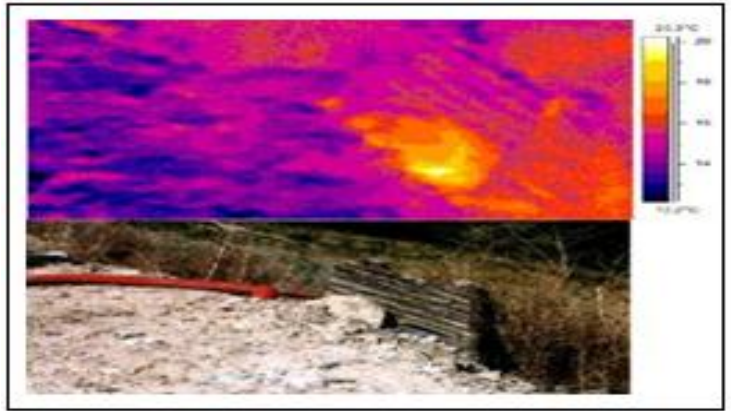

Fig. 5. Composting place

\subsection{Fire protection}

Thermal imaging systems help to find victims in dense smoke or darkness, to seek epicenter of the fire by observation of hot gases. After extinguishing the fire they are used to detect and rescue victims and to discover hidden fires and hazards.

Examples of use:

- detection of hidden and obvious fire sources,

- search and rescue victims,

- indication of the latent danger.
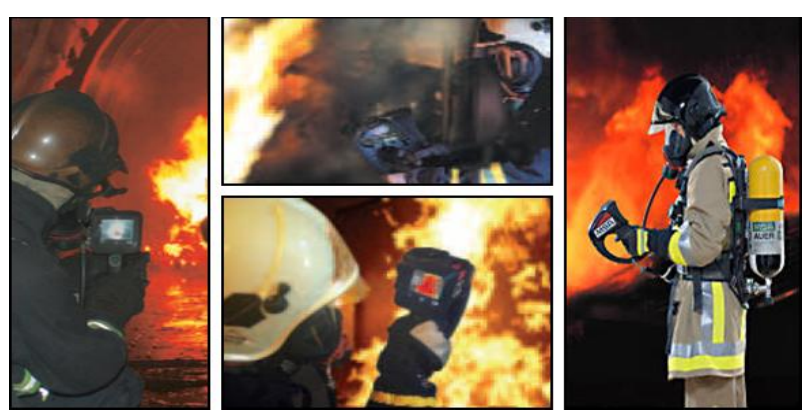

Fig. 6. Fire protection and IR

\section{CONCLUSION}

Researchers are working on a new methodology of buildings' thermal imaging, including new buildings, plus old ones which are being reconstructed. The best methodology improves quality of building's repair, helps to choose appropriate materials for repair and check the finished works for possible heat leaks. The article was created on the basis of solving KEGA 3/7426/09 project.

\section{REFERENCES}

Blundell, S. \& Blundell, K. (2006): Concepts in Modern Physics. ISBN 978-0-19-856769-1. Oxford University Press

Miller \& Friedman (2004): Photonic Rules of Thumb. ISBN 978-0-44-201210-6

Svoboda, J. \& Straka, J. (2004): Nové trendy v prediktívní údržbě, diagnostike a monitoringu elektrických strojov a prvků. Proceedings of the 5th ELEKTRO 2004, Žilina

Saunders, P. (2007): Radiation Thermometry. Fundamentals and Applications in the Petrochemical Industry. ISBN 978-0-8194-6783-6. SIPE

Šimko, M. \& Gutten, M. (2003): Diagnostika transformátorov termovíziou. ISBN 80-248-0210-4. Diago, TU-VŠB Ostrava 